\title{
El juramento socrático de la profesión docente
}

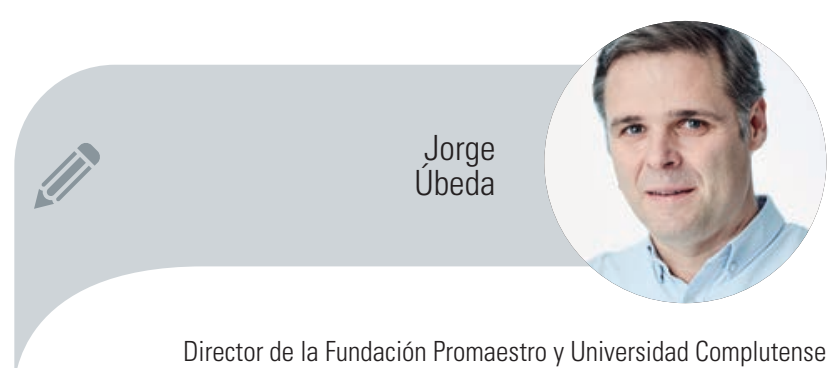

jubeda@promaestro.org

Si los médicos hacen un juramento, solemne y público, por el cual se comprometen a respetar una serie de valores científicos y morales en el ejercicio de su profesión, y se acogen al patrocinio del gran médico que fue Hipócrates, los profesores también podríamos culminar nuestra formación con algún juramento similar en el que quizá la figura que nos inspirara fuera la de Sócrates. Aquel famoso ateniense, perseguido, juzgado y condenado a muerte por querer que sus ciudadanos se ocuparan de aprender lo que de verdad importa, iniciaba cada día de su vida buscando alguien a quien enseñar cómo seguir aprendiendo, cómo hacer cada día las preguntas que merecen la pena ser respondidas y cómo someter a juicio las propias ideas y creencias. En definitiva, el juramento socrático, como el hipocrático, habla de que el factor más importante en nuestra profesión es el factor humano y que si este falla, se produce un daño mayor que aquel que la educación, o la salud, pretendía prevenir o curar.

Corren tiempos de incertidumbre para la educación escolar y para los profesores, fruto de la pandemia provocada por la COVID-19 que ha confinado países enteros y ha forzado a cerrar la asistencia a las escuelas, institutos y universidades. Todo ello ha obligado a que los docentes trasladen, de la noche a la mañana, las aulas de sus centros y las programaciones al entorno digital. No tenemos todavía datos sobre lo que está pasando en nuestro sistema educativo durante este proceso, pero hay algo que resulta fácil adivinar: el compromiso profesional de la mayoría de las maestras y profesores está fuera de toda duda. Un compromiso que no ha esperado a tener las mejores condiciones para continuar ofreciendo oportunidades de aprendizaje a sus alumnos y que está buscando, en todo momento, que todos puedan seguir aprendiendo.

El compromiso de los docentes, corazón de su juramento socrático, no debe confundirse con la vocación. La vocación habla más de una dimensión in-

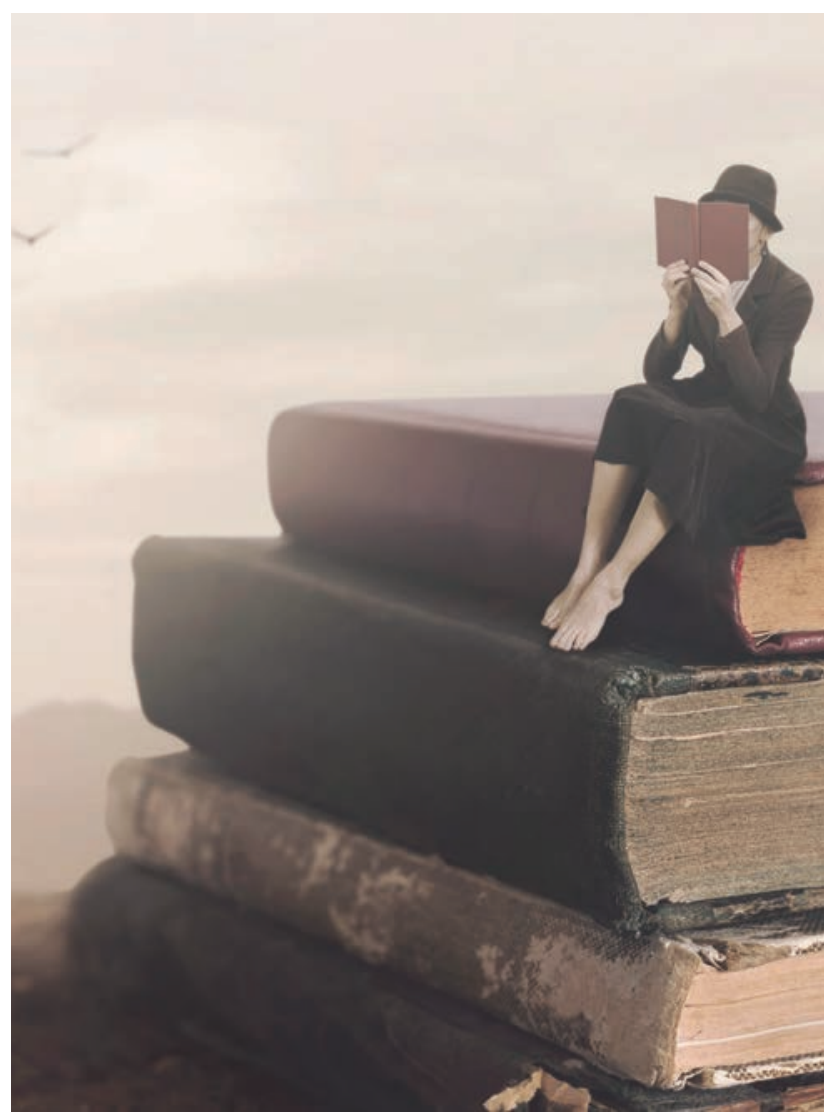

dividual de la profesión docente, bien estudiada, que se refiere a la autocomprensión de la vida profesional como llamada a dejar una huella en nuestros alumnos. Esta llamada alimenta la práctica educativa de muchos docentes, conviene cuidarla y no desaparece cuando se termina el ejercicio profesional. El compromiso, sin embargo, habla de una dimensión social que se alimenta, precisamente, de la comunidad profesional que construimos con otros docentes, incluso más allá de aquellos con los que compartimos claustro y centro escolar. Me atrevería a sostener, incluso, que el compromiso profesional de los docentes es necesario, incluso en ausencia de una clara vocación a la enseñanza.

Quisiera destacar dos ingredientes que considero esenciales en este compromiso profesional o juramento socrático. Tenemos un compromiso con el conocimiento y sus valores - destacando entre ellos la veracidad, el rigor, el método, la utilidad, la belleza, el progreso, la argumentación, el pluralismo- pues consideramos que la cultura es un bien común que nos convierte en ciudadanos responsables, libres 


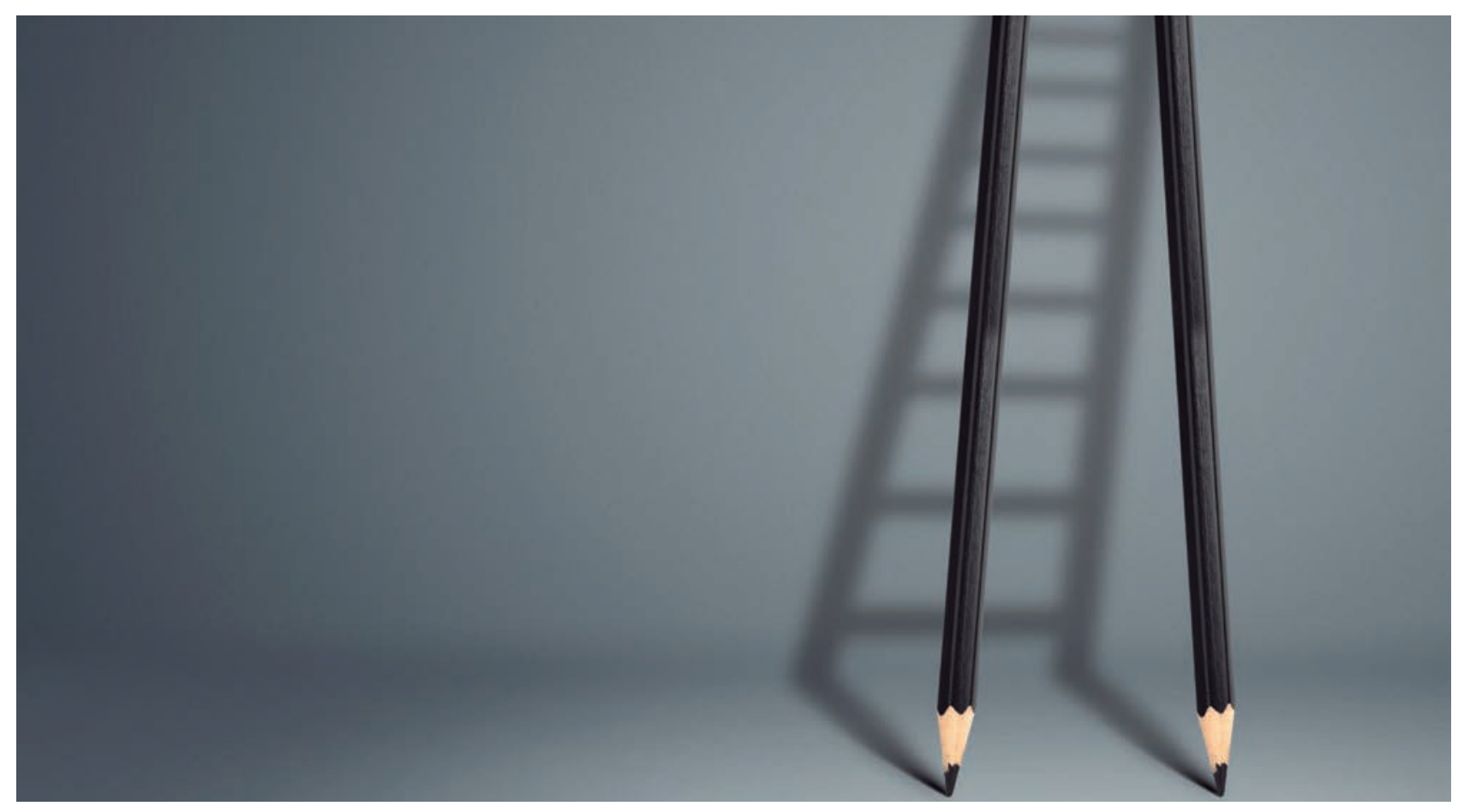

y más pacíficos con capacidad para comprender el mundo, actuar en él y proponer transformaciones que lo puedan mejorar. Durante estas semanas de educación confinada la mayoría de los profesores se han preguntado por el sentido de un currículo sobrecargado, que fomenta una adquisición mecánica de los conceptos comprendiendo a los alumnos como meros receptores del conocimiento. ¿A qué esperamos para hacer valer frente a las autoridades educativas lo que sabemos desde hace tiempo y que esta crisis ha hecho evidente? ¿No nos damos cuenta de que es este compromiso con el conocimiento lo que nos constituye como docentes?

Pero no solo nos conciernen los conocimientos que han de ser necesarios para que las personas se desempeñen bien y de modo integral en la sociedad, pues el conocimiento educativo, aquel que nos ayuda a hacer mejor nuestro trabajo y que provienen de la práctica docente y la investigación nos son muy necesarios. Sin embargo, en este punto todavía discutimos muy poco acerca del impacto educativo de nuestras prácticas, apenas abrimos nuestras aulas a la observación rigurosa de otros mientras que la investigación educativa parece vivir en una realidad ajena a las escuelas y sus retos cotidianos. Si queremos tener una voz autorizada sobre la educación tenemos el deber profesional de construir comunidad profesional docente basada en la observación discutida de nuestra práctica y las evidencias que provienen de la investigación educativa. Si no lo hacemos nosotros no me cabe ninguna duda que otros lo harán en nuestro nombre, secuestrando nuestra voz profesional y nuestro conocimiento. Lo estamos viendo en estos días en las decisiones educativas que se pro- ponen desde una ausencia notable de nuestra voz, conocimiento y experiencia.

Si el conocimiento, en este doble sentido, es esencial al compromiso docente, la relación con los alumnos también lo es pues sabemos que sin interacción social entre profesor y estudiantes y de los estudiantes entre sí es imposible que se despierten y consigan los aprendizajes que buscamos en la escuela. No somos solo una profesión de conocimiento, también lo somos de relación humana, por lo que el cuidado de todos los aspectos personales, emocionales y afectivos que contribuyen a la educación de nuestros alumnos es indispensable para un ejercicio adecuado de nuestra profesión. Durante estas semanas se han puesto a prueba nuestras relaciones con los alumnos, pues la interacción digital no puede suplir a la personal y menos con aquellos alumnos con menos recursos tecnológicos, cognitivos y personales para ello. Si nos estamos planteando una escolarización híbrida para el curso que viene, es el momento de compartir entre nosotros qué es lo que nos está funcionando mejor, qué es lo que nos falla en este momento y cómo podríamos hacerlo mejor en el futuro.

Nuestro juramento socrático, basado en el conocimiento y la relación, es la base sólida para responder al reto permanente de la educación, un reto que ha tomado hoy el rostro de una pandemia llevando nuestras escuelas fuera de ellas al espacio virtual. Necesitaremos tecnologías digitales, con todas las garantías posibles de protección de los menores, para dar una respuesta educativa adecuada en esta situación. Pero el factor decisivo seguiremos siendo nosotros, los maestros y profesoras, la comunidad profesional docente que actualizará, cada día, su juramento socrático • 